\title{
Impact of rainfall fluctuations and temperature variations on people movement in Sub-Saharan Africa: A Time Series Analysis of data from Somalia and Ethiopia
}

\author{
Omar Moalin Hassan ${ }^{1}$, Gurudeo Anand Tularam² \\ ${ }^{1}$ Research Associate - Environment Futures Research Institute, Griffith University, Brisbane, Australia. \\ ${ }^{2}$ Senior Lecturer - Mathematics and Statistics, Griffith Sciences (ENV), Environment Futures Research \\ Institute (EFRI), Griffith University, Brisbane, Australia. \\ Email: omar.moalinhassan@griffithuni.edu.au
}

\begin{abstract}
Water is highly critical for the existence of humans and other living organisms as well as for all sorts of life. Agriculture needs water to produce crops and manufacturing industries need it for producing products and services. Water is immensely critical for energy production and needed in the balance and sustainability of ecosystem. There has been a considerable rainfall variations that impacted water availability in Somalia and Ethiopia. Equally, temperature variations have also played a major role in the everyday life of Somalis and Ethiopians. Together the rainfall fluctuations and temperature variations have been attributed to climate change. The effects of these issues on people movements away from rural to urban have had little attention in recent times. This paper addresses the impact of climate change variables on rural - urban migration in both Somalia and Ethiopia. More specifically, we use time series analysis to examine the interactions between the rural-urban migration, rainfall and temperature. We model the multivariate data using ARIMA and VAR models; this is to first conduct univariate analyses for the purpose of predictions, and secondly to understand the nature of interactions and dependencies by conducting multivariate VAR analysis. This study determines the most appropriate ARIMA models of rural migration, urban migration rainfall and temperature of Somalia and Ethiopia as presented in Table 2. Both ARIMA and VAR analyses have produced relatively good models that are statistically significant and perform well in making short term predictions; a 10 year period of annual forecast of rural and urban migration as well as rainfall and temperature of Somalia and Ethiopia were carried out. Then univariate and multivariate analyses have showed that climate change factors such as "rainfall" and "temperature" variations have a combined granger effect on people migration in both rural and urban areas in both countries; in fact temperature variations have a significant impact (5\% and 10\%) on urban and rural migrations respectively. Climate change effects appear to be driving the migration from rural to urban. This is also compounding the international migration out of the African continent that is noted in Europe, Asia and even Australia.
\end{abstract}

Keywords: Sub-Saharan Africa, water security, rural-urban migration, climate change, time series 


\section{INTRODUCTION}

The world's population has been increasing dramatically in recent years. In the 1950s the world population was around 2.5 billion people (Miller et al., 2016). During the past six decades this has grown to exceed seven billion people (Schramski et al., 2015), and is now projected to reach about 11 billion by the end of the $21^{\text {st }}$ century (Bongaarts, 2015; Jones and Warner, 2016). Similarly, the Sub-Saharan African (SSA) population has been increasing rapidly in recent years. SA population was less than 200 million in 1950; in 2012 SSA population reached approximately 900 million (Tularam and Hassan, 2016a; 2016b). In fact, the population in Sub-Saharan Africa quadrupled during the period between 1950 and 2010, increasing from 179 million in 1950 to 830 million in 2010 (Tularam and Hassan, 2016a; 2016b). Urbanization has been growing rapidly throughout the world. In 1950 about 733 million of world's population lived in urban areas. Five decades later in 2000, the number of the people living in cities had increased to 2.857 billion in 2000 , about $47.1 \%$ of the world's population (Cohen, 2006). In Sub-Saharan Africa 11\% of the population lived in urban areas in 1950; it is projected that 49\% SSA population will live in cities in 2025 (Bigombe and Khadiagala, 2004). SSA experiences rainfall fluctuations and higher average temperatures that impact on agricultural production (Bello et al., 2012). In SSA low average annual rainfall, increasing average temperatures and low agricultural production have been noted since 1970s. A rise in temperatures and potential evapotranspiration rates compounded with decreasing precipitation trigger an increase in the length and severity of droughts in SSA (Mullan, et al., 2005). In East Africa, climate change has impacted on rainfall amounts and temperature levels; the frequency of dramatic rain events and dire dry seasons has increased considerably (Cechvala, 2011; Dilling et al., 2015).

A large amount of the literature had indicated the existence of strong connections between climate change conditions and patterns human migration and settlement (McLeman and Smit, 2006). Barrios et al. (2006) and Laczko and Aghazarm (2009) examined whether environmental change shapes urbanization in SSA and found that climate change -as represented by rainfall- has transformed urbanization in Sub-Saharan Africa and that the relation between climate change and urbanization has become stronger. Reuveny (2007) suggested that several environmental factors such as deforestation, desertification, droughts, famines, floods, land degradation, soil erosion and water scarcity have caused environmental migration in many parts of SSA. In Western Sudan, during times of low rainfall that hinder agricultural production; male household members often migrate to Khartoum in search of employment opportunities to earn income mainly from non-farm related activities (Afolayan and Adelekan, 1999). Marchiori et al. (2012) found that a minimum of about 5 million people have migrated between 1960 and 2000 due to anomalies in local weather in SSA. This represents 0.3 per thousand individuals or 128,000 people every year. Somalia is considered to be one of the most vulnerable countries to climate change in the world (Kolmannskog, 2009). The main components and livelihoods of the economy are rain-fed agriculture and livestock; directly depend on the environment and weather conditions. Droughts and floods have become more frequent in Somalia. Due to unmitigated exposure to climate stress and decreasing resources, Somalia people have been experiencing involuntary migration and large scale displacement (Meeking, 2013). Evidence shows that drought has significant consequences on the mobility of the rural communities living in the Ethiopian highlands (Gray and Mueller, 2012). Migration has been a strategy to adapt the impact of climate change on rural communities in SSA (McLeman and Smit, 2006). Similarly rural communities in dryland areas of Ethiopia tend to migrate during drought periods (MezeHausken, 2000). A large number of rural people migrated to cities during Ethiopia's large scale famines in 1980s (Ezra, 2001).

The annual internal renewable water resources in SSA is estimated to be around 3.7 billion $\mathrm{m}^{3}$ (ADF VII, 2010). The region withdraws less than $2 \%\left(55\right.$ million $\mathrm{m}^{3}$ ) of the available internal fresh water resources annually. The per capita annual internal renewable water resources in SSA is $7488 \mathrm{~m}^{3}$-well above the minimum threshold of $1000 \mathrm{~m}^{3} /$ year (35318.3 $\mathrm{ft}^{3} /$ year) (Tularam and Marchisella, 2014). Yet, about half of the population in SSA have no access to clean water (Reuveny, 2007). Table 1 presents comparison of the proportional changes in area, total population and proportion of water available within each of three classes of water availability, for 2000 and 2025 . The data are presented as percentages, and refer only to the African continent and exclude the islands of the Indian Ocean (Comores, Madagascar, Mauritius, Reunion and Seychelles).

Somalia has generally high mean air temperatures throughout the year with some variation to temperature distributions; southern parts of the country record highest temperatures in the country, for example, Muchiri (2007) reported that temperatures in the inland south of the country are the highest in Oct - April. Afgoi, Afmadow and Belet Weyne have higher temperatures in these months; similarly, Luuq has the highest mean temperature in the country of over $30.5^{\circ} \mathrm{C}$, followed by Berbera and Bossaso that have considerably high temperatures that reach $35-38^{\circ} \mathrm{C}$ between June and August. Temperatures along the southern coast however, 
seem to be lower than those of the inland areas; that may be due to the impact of low temperature ocean currents. Northern parts of the country tend to have lower annual means. Marchiori (2011) found that climate variations have resulted in thousands of net migration in 43 SSA countries including Somalia and Ethiopia every year. On the other hand, Ethiopia characterises generally medium high mean air temperatures throughout the year as well as considerable temperature variation over Ethiopia. Eastern parts of Ethiopia appear the highest temperatures in the country, for instance average temperatures in Gode and Dire Dawa of the Somali Region of Ethiopia range between $27-30^{\circ} \mathrm{C}$ most of the year. In contrast to that, Addis Ababa and Jimma have average monthly temperatures that are below $21{ }^{\circ} \mathrm{C}$ throughout the year.

Table 1. Comparison of the proportional changes in area, total population and proportion of water available within each of three classes of water availability, for 2000 and 2025 (Ashton, 2002).

\begin{tabular}{|c|c|c|c|c|c|c|}
\hline \multirow{2}{*}{ Countries with water } & \multicolumn{3}{|l|}{2000} & \multicolumn{3}{|l|}{2025} \\
\hline & Area \% & Population \% & Water $\%$ & Area \% & Population \% & Water $\%$ \\
\hline Abundance & 52.5 & 60.8 & 95.2 & 34.7 & 23.9 & 78.3 \\
\hline Deficit & 21.5 & 14.9 & 0.4 & 26.2 & 18.8 & 1.1 \\
\hline Total African population & \multicolumn{3}{|c|}{786 million } & \multicolumn{3}{|c|}{1428 million } \\
\hline
\end{tabular}

This study examines the impact of rainfall and temperature variations on the movement of people in SubSaharan Africa (SSA) in general but reports on Somalia and Ethiopia in particular. The study aims to investigate patterns of rural migration, urban migration, rainfall and temperature and to forecast trends for the next 10 year period by using ARIMA. It also aims to examine the relationship between climate change and people movement variables only for Somalia and Ethiopia (an example) using VAR; the analysis will compare and contrast cause and effect in the patterns of times series concerning the variables relating to the two countries. The next section describes Somalia and Ethiopia in detail; their geography and climate conditions. These two countries are an example of analyses completed for other countries in SSA. This is followed by a brief section on methods, analyses and results and finally, discussion and conclusion completes this brief paper.

\section{METHODS}

This study uses autoregressive integrated moving average (ARIMA) that is univariate time series model. This study initially examines and analyses water rainfall, temperature as well as people movement of Somalia and Ethiopia using the ARIMA model also called Box-Jenkins model (Nury, et al., 2013). A model is classified as autoregressive integrated moving average $\operatorname{ARIMA}(\mathrm{p}, \mathrm{d}, \mathrm{q})$. When the original time series data $X_{t}$ appears to be non-stationary then it is made stationary by taking $d$ non-seasonal differences (in most cases $d=1$ or 2); so then an $\operatorname{ARMA}(p, q)$ model is stationary time series which we can label: $d X_{t}=Y_{t}$ and $Y_{t}$ can be written as Equation 1.

A vector auto-regression (VAR) multivariate time series model is developed to study interdependencies, impulse responses, and granger causality interaction type analyses. Suppose that $Y_{t}=\left(Y_{1, t}, Y_{2, t}, \ldots, Y_{k, t}\right)^{\prime}$ represents a time series variable vector $(k \times 1)$ then an autoregressive model of the basic vector, having order $p$, $\operatorname{VAR}(p)$ becomes Equation 2.

$$
\begin{array}{rr}
\text { ARIMA* } & Y_{t}=c+\alpha_{1} Y_{t-1}+\cdots+\alpha_{p} Y_{t-p}+\varepsilon_{t}+\theta_{1} \varepsilon_{t-1}+\cdots+\theta_{q} \varepsilon_{t-q}, \\
\text { VAR** }^{* *} & Y_{t}=c+\prod_{1} Y_{t-1}+\prod_{2} Y_{t-2}+\ldots+\prod_{p} Y_{t-p}+u_{t},
\end{array}
$$

* where $c$ is a constant term, $\alpha_{i}$ an autoregressive parameter, $\theta_{i}$ moving average parameter, and $\varepsilon_{t}$ as the error term (moving average).

** where $t$ is $1, \ldots, \mathrm{T}$, with $Y_{t}$ being $(k \times 1)$ and $\prod_{i}$ are coefficient matrices, $c$ a $(k \times 1)$ constant vector and $u_{t}$ a $(k \times 1)$ vector process for white noise with an unobservable zero mean, with $\sum$ covariance matrix.

Granger causality test: The VAR structure gives information on the ability of variables or variable groups to forecast. Granger (1969) introduced this intuitive notion of a variable's ability to forecast. Should $Y_{1}$ variable or variable groups be instrumental in another $Y_{2}$ variable's or variable group's prediction, then $Y_{1}$ Grangercauses $Y_{2}$. In the opposite case, $Y_{1}$ does not Granger-cause $Y_{2}$ if for all $s>0$ the mean squared error of a forecast of $Y_{2, \mathrm{t}+\mathrm{s}}$ based on $\left(Y_{2, \mathrm{t}}, Y_{2, \mathrm{t}-1}, \ldots\right)$ is the same as the mean squared error of a forecast of $Y_{2, \mathrm{t}+\mathrm{s}}$ based on $\left(Y_{2, \mathrm{t}}, Y_{2, \mathrm{t}-1}, \ldots\right)$ and $\left(Y_{1, \mathrm{t}}, Y_{1, \mathrm{t}-1}, \ldots.\right)$. It is worth noting that Granger's causality notion only suggests the ability to forecast. $\operatorname{A~} \operatorname{VAR}(p)$ bivariate model for $Y_{\mathrm{t}}=\left(Y_{1 \mathrm{t}}, Y_{2 \mathrm{t}}\right)^{\prime}$, sees the failure of $Y_{2}$ to Granger-cause $Y_{1}$, 
given that all $p$ VAR matrices of coefficients are lower triangular. The Wald statistic can test $p$ linear restrictions on coefficients. The coefficient matrices of VAR are diagonal in the event that both $Y_{2}$ and $Y_{1}$ fail to Granger-cause each other. In essence, how and in what manner do the other variables contribute to the prediction process of a given variable; that is, which variables or which information is crucial for the prediction process.

\section{DATA SOURCES}

The Sub-Saharan African countries examined in this study are Somalia (SOM) and Ethiopia (ETH). This study uses climate change and people movement (rural-urban migration) data of Somalia and Ethiopia over a fiftysix year period from 1960 to year 2015. Rainfall and temperature are used as climate change proxy variables. Rainfall and temperature time series data was collected on monthly bases from the National Oceanic and Atmospheric Administration (NOAA) of USA https://www.ncdc.noaa.gov/cdo-web/ and the World Bank (climate change knowledge portal: http://sdwebx.worldbank.org/climateportal/ and then converted to annual terms (1960-2015). Due to migration data availability issues in Somalia and Ethiopia; the annual population data (rural, urban and total populations) was collected from the World Bank http://data.worldbank.org/. The vital statistics method has been used to indirectly measure the net internal migration (rural-unban) of Somalia and Ethiopia. The yearly natural growth rate of the population in each country was accounted for and through this process the migration data was obtained (Sharma, 2004). The time series data in this model consist of four variables that are Rural Migration (MR), Urban Migration (MU), Rainfall (Rain) and Temperature (Temp). People movement data namely MR and MU are the dependent variables, while Rain and Temp are independent variables. The data was initially prepared in excel spreadsheets and then transferred to Stata. Stata is a comprehensive, integrated statistical software package that is used for data management, data analysis and to produce graphics to visualize the data; Stata was developed in 1985 by Stata Corporation. Hashizume et al. (2008) utilized Stata software for rainfall and temperature time series analyses; similarly Ebrahim et al. (2011) suggested the appropriateness of Stata software for the analyses of migration time series data.

\section{RESULTS AND DISCUSSION}

The ARIMA model is developed for the following order rural migration (MR), urban migration (MU), rainfall (Rain) and temperature (Temp). The following section presents results of the analysis time series data of rural and urban migration of Somalia to predict how rural and urban migration time series may change in the future; a similar process was used to forecast rainfall and temperature. For example, Figure 1 shows the autocorrelation $\mathrm{ACF}$ and partial autocorrelation PACF of rural and urban migrations of Somalia.

The univariate analysis of MR, MU, Rain and Temp of Somalia and Ethiopia aimed to forecast the annual trend that these variables may have in the decade between 2016 and 2025; ARIMA was used to find the best fit of the model and their appropriateness were diagnosed and checked by testing ACF and PACF of residuals. AIC and $\mathrm{BIC}$ results proved the usefulness and adequacy of the ARIMA models. Augmented Dickey-Fuller unit root test (ADF) and the White Noise test in the stationarized time series through autocorrelation and partial autocorrelation also gave favorable results. The analysis of the data have proven that lags of stationarized time series data and that of the forecast errors terms are useful tools to predict the trend that their respective variable will have in the future. ARIMA models
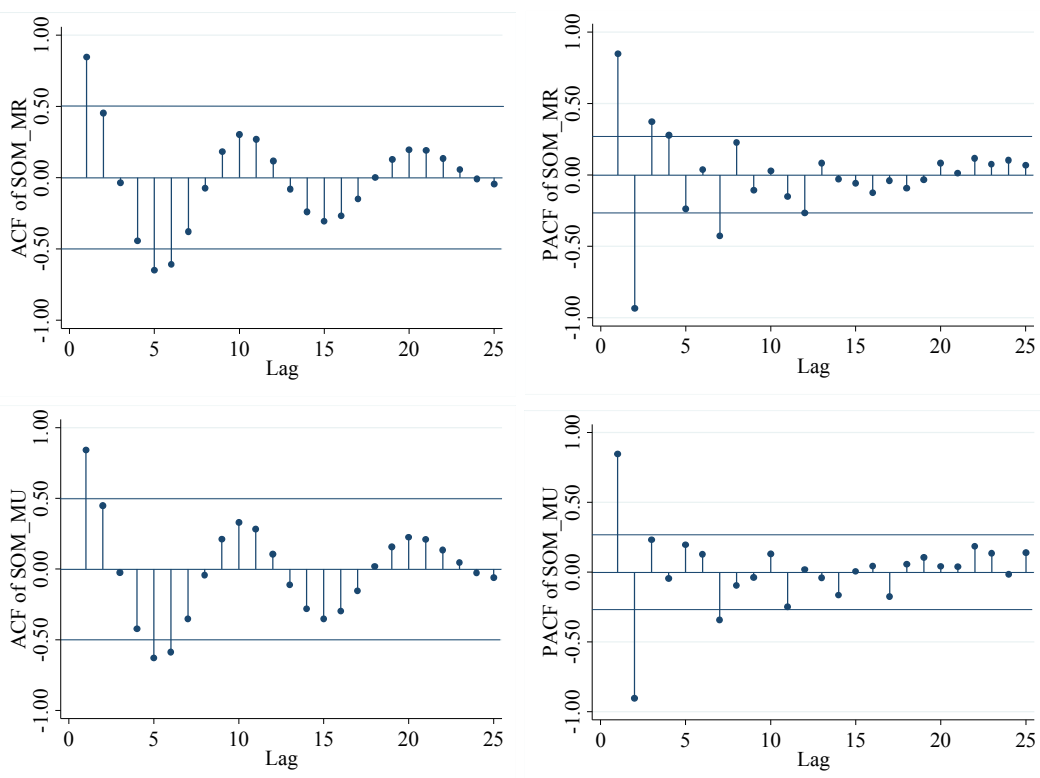

Figure 1. ACF and PACF Plots of rural and urban migration time series of Somalia 
obtained for MR, MU, Rain and Temp of Somalia and Ethiopia together with their corresponding AIC, BIC and P-values as well as Equations (Table 2) were then used to forecast changes of the time series variables in the next 10 years $(2016-2025)$.

Table 2. Equations used to predict MR, MU, Rain and Temp of Somalia and Ethiopia.

\begin{tabular}{|c|c|c|c|c|c|}
\hline Country & Equation & ARIMA & AIC & BIC & Prob. \\
\hline \multirow[t]{4}{*}{ Somalia } & $M R_{t}=-355+1.59 M R_{t-1}-0.889 M R_{t-2}+0.223 \theta \varepsilon_{t-1}+\varepsilon_{t}$ & $\begin{array}{l}(2,0,1) \\
(2,1,1)\end{array}$ & 1133.12 & 1143.06 & 0.000 \\
\hline & $D M U_{t}=73.25+1.55 D M U_{t-1}-0.877 D M U_{t-2}-0.753 \mathrm{D} \theta \varepsilon_{t-1}+\varepsilon_{t}$ & $\begin{array}{l}(2,0,1) \\
(2,1,1)\end{array}$ & 1052.96 & 1062.91 & 0.000 \\
\hline & $\begin{aligned} \text { D2Rain }_{t}=0.005- & 0.564 \mathrm{D} 2 \operatorname{Rain}_{t-1}-0.497 \mathrm{D} 2 \operatorname{Rain}_{t-2} \\
& -0.437 \mathrm{D} 2 \text { Rain }_{t-3}-0.996 \mathrm{D} 2 \theta \varepsilon_{t-1}+\varepsilon_{t}\end{aligned}$ & $(3,2,1)$ & 569.79 & 579.73 & 0.000 \\
\hline & $\operatorname{DTemp}_{t}=0.0083-0.789 \mathrm{DTemp} p_{t-1}+\varepsilon_{t}$ & $(1,1,2)$ & -5.046 & 2.983 & 0.000 \\
\hline \multirow[t]{4}{*}{ Ethiopia } & $M R_{t}=6575.834+1.46 M R_{t-1}-0.76 M R_{t-2}-0.68 \theta \varepsilon_{t-1}+\varepsilon_{t}$ & $(2,0,2)$ & 1307.81 & 1319.85 & 0.000 \\
\hline & $M U_{t}=7615.92+0.217 M U_{t-1}+\varepsilon_{t}$ & $(1,0,0)$ & 1259.6 & 1265.65 & 0.000 \\
\hline & $\begin{aligned} \text { D2Rain }_{t}=0.012- & 0.427 \text { D2Rain }_{t-1}-0.436 \mathrm{D} 2 \text { Rain }_{t-2} \\
& +-0.26 \mathrm{D} 2 \text { Rain }_{t-3}-.999 \mathrm{D} 2 \theta \varepsilon_{t-1}+\varepsilon_{t}\end{aligned}$ & $(3,2,1)$ & 611.66 & 621.61 & 0.000 \\
\hline & $\begin{array}{l}\text { D2Temp } \\
\varepsilon_{t}=0.001068-0.36823 \text { D2Temp } \\
t-1-0.54735 \mathrm{D} 2 \text { Temp }_{t-2}+\end{array}$ & $(3,2,1)$ & 23.82 & 33.76 & 0.000 \\
\hline
\end{tabular}

Figure 2 shows slight decrease of rural migration in Somalia until early 2020s followed by a period of increased people movement in rural areas until 2025. Similarly, Figure 3 indicates a period of slow down to the urban migration of Somalia, followed by a period that people movement to urban areas will take an increasing trend from early 2020 s.

The following section presents VAR results of the time series analysis of Rain and Temp of Ethiopia to assess how Rain and Temp time series may change in the future, a similar process was used to forecast rural and urban migration. The first step of the VAR analysis was the lag selection process and it suggested that lag 3 was the most suitable option. Then VAR analysis was conducted to assess the interaction between the variables or how one variable can explain another variable.

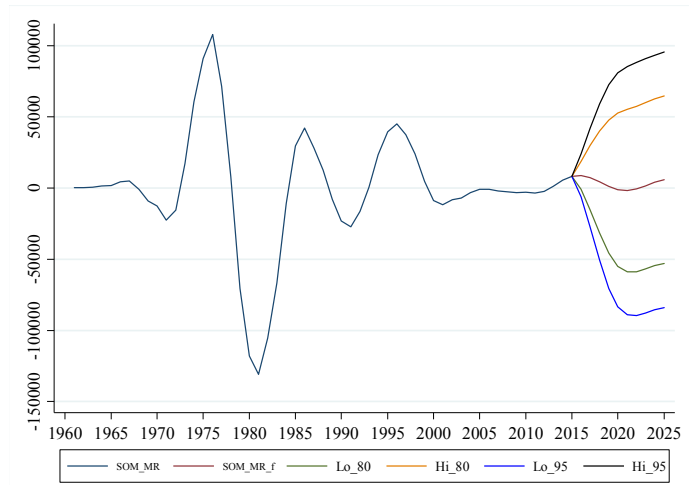

Figure 2. Somalia MR time series and forecast 20162025 [ARIMA $(2,0,1)]$

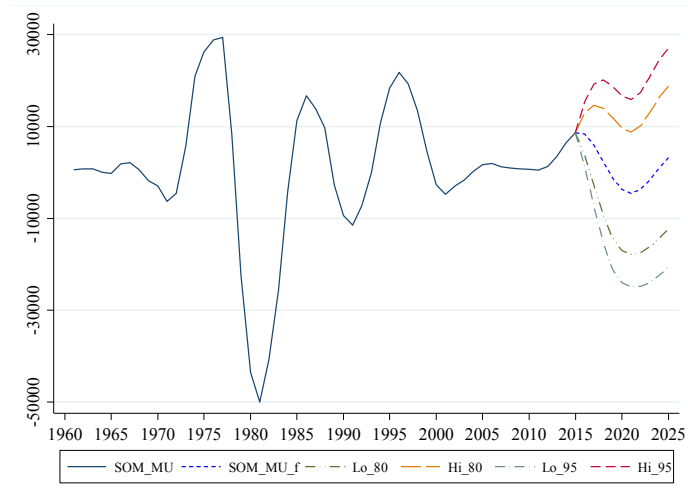

Figure 3. Somalia MU time series and forecast 20162025[ARIMA $(2,1,1)]$

Table 3. Model fitting for the VAR model for MR, MU, Rain and Temp of Ethiopia.

\begin{tabular}{lrrrrr}
\hline Equation & Parms & \multicolumn{1}{c}{ RMSE } & R-sq & \multicolumn{1}{c}{ chi $^{2}$} & P-value \\
\hline MR & 5 & 61718.2 & 0.3833 & 33.55988 & 0.000 \\
MU & 5 & 58059.8 & 0.1425 & 8.971873 & 0.062 \\
Rain & 5 & 53.8556 & 0.2152 & 14.80316 & 0.005 \\
Temp & 5 & 0.327795 & 0.6557 & 102.8537 & 0.000 \\
\hline
\end{tabular}

Results obtained from the VAR model testing have suggested that future amounts of MR and MU in Ethiopia can be predicted by using Equations (3 and 4). The results have shown the existence correlation between MR, MU, Rain and Temp. Granger causality tests were conducted to test the VAR model and to determine whether each variable plays a significant role in each of the equations. The granger causality test shows that there is 
significant granger causality effect from Temp to MR (10\%) and MU (1\%). Further, Temp may able to compensate for the other variables and lead to a combined granger effect on MR and MU. Table 4 presents granger causality Wald tests results.

$$
\begin{gathered}
E T H_{-} M R_{t}=-748022+0.81 M R_{t-1}+0.54 M U_{t-1}+136.855 \text { Rain }_{t-1}+28050.44 \text { emp }_{t-1}+e_{t} \\
E T H_{-} M U_{t}=-1095298+0.08 M R_{t-1}+0.1 M U_{t-1}+101.51 \text { Rain }_{t-1}+44725.46 \text { Temp }_{t-1}+e_{t}
\end{gathered}
$$

Table 4. Granger causality Wald tests

\begin{tabular}{lcccc}
\hline Dependent variable & Variables & chi $^{2}$ & df & P-value \\
\hline MR & MU & 2.127 & 1 & 0.145 \\
MR & Rain & 0.860 & 1 & 0.354 \\
MR & Temp & 2.855 & 1 & $\mathbf{0 . 0 9 1}$ \\
MR & ALL & 6.268 & 3 & $\mathbf{0 . 0 9 9}$ \\
\hline MU & MR & 0.333 & 1 & 0.564 \\
MU & Rain & 0.535 & 1 & 0.465 \\
MU & Temp & 8.202 & 1 & $\mathbf{0 . 0 0 4}$ \\
MU & ALL & 8.255 & 3 & $\mathbf{0 . 0 4 1}$ \\
\hline
\end{tabular}

\section{CONCLUSION}

This paper examines rainfall fluctuations and temperature variations in Somalia and Ethiopia and assesses climate change impact on rural and urban migration. Univariate ARIMA models and multivariate VAR models were developed. The ARIMA models of MR, MU, Rain and Temp were used to predict annual change of Rural-Urban Migration, Rain and Temp (2016-2025). The study predicts that Somalia will experience a slight decrease of both rural and urban migrations until 2020; followed by slight increasing trend in both. In Somalia, average rainfall is expected to remain relatively stable, while the average temperatures are expected to fluctuate considerably. Further, rural migration is predicted to relatively low in Ethiopia while an average of 7665 people will move to urban Ethiopia annually in the next 10 years. The forecast shows decreasing average annual rainfall and increasing average annual temperature in Ethiopia. Moreover, the granger causality test shows that there is significant granger causality effect from Temp to MR and MU; and Rain and Temp have a combined granger effect on MR and MU. The results suggested that rainfall fluctuations as well as raising temperatures have contributed to the people movement in Somalia and Ethiopia. Hence, the climate change appears to impact rural-urban migration in Somalia and Ethiopia. This finding is in line with that of Marchiori et al. (2011) and Tularam and Hassan (2016a, 2016b). Migration data availability and interpretation have been a challenge for researchers. The study also utilized annual average rainfall and temperature at country level. Therefore, there is a need for further studies that examine the impact of climate change and the migration phenomenon in all other countries in SSA.

\section{REFERENCES}

ADF VII, (2010). Climate Change and Ecosystem Sustainability: Acting on Climate Change for Sustainable Development in Africa, Seventh African Development Forum, Issues Paper \#9. ADF VII • 10 - 15 October 2010 - United Nations Conference Centre • Addis Ababa, Ethiopia.

Afolayan, A. A. and Adelekan, I.O. (1999). The role of climatic variations on migration and human health in Africa. The Environmentalist, 18(4), pp.213-218.

Ashton, P.J. (2002). Avoiding Conflicts over Africa's Water Resources, Division of Water, Environment \& Forestry Technology, Pretoria, South Africa. Ambio, 31(3): 236-242 (2002). pp. 6

Barrios, S. Bertinelli, L. and Strobl, E. (2006). Climatic change and rural-urban migration: The case of subSaharan Africa. Journal of Urban Economics, 60(3), pp.357-371.

Bello, O. B. Ganiyu, O. T. Wahab, M. K. A. Afolabi, M. S. Oluleye, F. Mahmud, J. Azeez, M. A. and Abdulmaliq, S. Y. (2012). Evidence of climate change impacts on agriculture and food security in Nigeria. International Journal of agriculture and Forestry, 2(2), pp.49-55.

Bigombe, B. and Khadiagala, G. M. (2003). Major trends affecting families in Sub-Saharan Africa. United Nations, major trends affecting families: A Background Document, pp.164-87.

Bongaarts, J. and Casterline, J. (2013). Fertility Transition: Is Sub-Saharan Africa Different? Population and Development Review, 38(s1), pp.153-168.

Cechvala, S. (2011). Rainfall \& Migration: Somali-Kenyan Conflict, the Inventory of Conflict \& Environment. ICE Case Number 256.

Cohen, B. (2006). Urbanization in developing countries: Current trends, future projections, and key challenges for sustainability. Technology in Society, 28(1), pp.63-80. 
Dilling, L. Daly, M. E. Travis, W. R. Wilhelmi, O. V. and Klein, R. A. (2015). The dynamics of vulnerability: why adapting to climate variability will not always prepare us for climate change. Wiley Interdisciplinary Reviews: Climate Change, 6(4), pp.413-425.

Dolgonosov, B. M. (2016). Knowledge production and world population dynamics. Technological Forecasting and Social Change, 103, pp.127-141.

Ebrahim, S. Kinra, S. Bowen, L. Andersen, E. Ben-Shlomo, Y. Lyngdoh, T. Ramakrishnan, L. Ahuja, R.C. Joshi, P. Das, S.M. and Mohan, M. (2011). Correction: The Effect of Rural-to-Urban Migration on Obesity and Diabetes in India: A Cross-Sectional Study. PLoS medicine, 8(5).

Ezra, M. (2001). Demographic responses to environmental stress in the drought-and famine-prone areas of northern Ethiopia. Population, Space and Place, 7(4), pp.259-279.

Gray, C. and Mueller, V. (2012). Drought and population mobility in rural Ethiopia. World Development, 40(1), 134-145.

Hashizume, M. Armstrong, B. Wagatsuma, Y. Faruque, A.S.G. Hayashi, T. and Sack, D.A. (2008). Rotavirus infections and climate variability in Dhaka, Bangladesh: a time-series analysis. Epidemiology \& Infection, 136(9), pp.1281-1289.

Jones, G. A. and Warner, K.J. (2016). The $21^{\text {st }}$ century population-energy-climate nexus. Energy Policy, 93, pp.206-212.

Kolmannskog, V. (2009). Climate change, disaster, displacement and migration: initial evidence from Africa. UNHCR, Policy Development and Evaluation Service.

Laczko, F. and Aghazarm, C. eds. (2009). Migration, environment and climate change: Assessing the evidence (pp. 7-40). Geneva: International Organization for Migration.

Marchiori, L. Maystadt, J. F. and Schumacher, I. (2011). May. The impact of climate variations on migration in sub-Saharan Africa. In CSAE $25^{\text {th }}$ Anniversary Conference.

McLeman, R. and Smit, B. (2006). Migration as an adaptation to climate change. Climatic change, 76(1-2), pp.31-53.

Meeking, E. J. (2013). A Study of Climate Change Induced Migration in Somalia.

Meze-Hausken, E. (2000). Migration caused by climate change: how vulnerable are people inn dryland areas?. Mitigation and Adaptation Strategies for Global Change, 5(4), pp.379-406.

Miller, M. D. Marty, M .A. and Landrigan, P. J. (2016). Children's Environmental Health: Beyond National Boundaries. Pediatric Clinics of North America, 63(1), pp.149-165.

Muchiri, P. W. (2007). Climate of Somalia. FAO-SWALIM Technical Report No. W-01. FAO-SWALIM: Nairobi, Kenya.

Mullan, B. Porteous, A. Wratt, D. and Hollis, M. (2005). Changes in drought risk with climate change. Prepared for Ministry for the Environment (NZ Climate Change Office) and Ministry of Agriculture and Forestry. NIWA Client Report: WLG2005-23.(National Institute of Water and Atmospheric Research, Wellington).

Nsiah-Gyabaah, K. (2003). Urbanization, Environmental Degradation And Food Security In Africa. In The Open Meeting of the Global Environmental Change Research Community, Montreal, Canada, 16-18 October 2003.

Nury, A. H. Koch, M. and Alam, M. J. B. (2013). Time Series Analysis and Forecasting of Temperatures in the Sylhet Division of Bangladesh. In 4th International Conference on Environmental Aspects of Bangladesh (ICEAB), August, pp. 24-26.

Reuveny, R. (2007). Climate change-induced migration and violent conflict. Political geography, 26(6), pp.656-673.

Schramski, J. R. Gattie, D.K. and Brown, J.H. (2015). Human domination of the biosphere: Rapid discharge of the earth-space battery foretells the future of humankind. Proceedings of the National Academy of Sciences, 112(31), pp.9511-9517.

Sharma, R. K. (2004): Demography and Population Problems. Atlantic Publication, New Delhi, India, pp.191.

Tularam, G. A and Hassan, O. M. (2016a). Groundwater Assessment, Modeling, and Management. Chapter 27: Water Availability and Food Security: Implication of People's Movement and Migration in Sub-Saharan Africa (SSA) M. Thangarajan, Vijay P. Singh (Eds). CRC Press New York, USA. pp. 405-426.

Tularam, G. A. and Hassan, O. M. (2016b). The vulnerable nature of water security in Sub-Saharan Africa (SSA) - A Country by Country Analysis. In Handbook on Africa: Challenges and Issues of the 21st century (pp. 47-83).

Tularam, G. A. and Marchisella, P. (2014). Water scarcity in Asia and its long term water and border security implications for Australia. International Practices for Protecting Water and Wastewater Infrastructure (Eds. Robert M Clark and Simon Hakim). Springer Publication: NY 